\title{
Valproate and risk of fracture in Rett syndrome
}

H Leonard, J Downs, L Jian, et al.

Arch Dis Child 2010 95: 444-448

doi: 10.1136/adc.2008.148932

Updated information and services can be found at:

http://adc.bmj.com/content/95/6/444.full.html

These include:

References This article cites 22 articles, 4 of which can be accessed free at: http://adc.bmj.com/content/95/6/444.full.html\#ref-list-1

Email alerting Receive free email alerts when new articles cite this article. Sign up in the service box at the top right corner of the online article.

Notes

To order reprints of this article go to:

http://adc.bmj.com/cgi/reprintform

To subscribe to Archives of Disease in Childhood go to:

http://adc.bmj.com/subscriptions 


\title{
Valproate and risk of fracture in Rett syndrome
}

\author{
H Leonard, ${ }^{1}$ J Downs, ${ }^{1}$ L Jian, ${ }^{1}$ A Bebbington, ${ }^{1}$ P Jacoby, ${ }^{1}$ L Nagarajan, ${ }^{2}$ D Ravine, ${ }^{3}$ \\ $\mathrm{H} \mathrm{Woodhead}^{4}$
}

${ }^{1}$ Telethon Institute for Child Health Research, Centre for Child Health Research, University of Western Australia, West Perth, Western Australia 2Department of Neurology, Princess Margaret Hospital for Children, West Perth, Western Australia

${ }^{3}$ West Australian Institute of Medical Research and Centre for Medical Research, University of Western Australia, West Perth, Western Australia ${ }^{4}$ Sydney Children's Hospital and School of Women's and Children's Health, University of New South Wales, Sydney, New South Wales, Australia

\section{Correspondence to}

Dr Helen Leonard, Telethon Institute for Child Health Research, Centre for Child Health Research, University of Western Australia, P0 Box 855, West Perth 6872, Western Australia: hleonard@ichr.uwa.edu.au

Accepted 22 November 2009

\begin{abstract}
Objectives Some associations between antiepileptic drugs (AEDs) and fracture risk have been reported in the general population. This study investigated the relationships between fracture risk and commonly used AEDs in Rett syndrome, a genetic disorder associated with intellectual and physical disability.

Study design Cases ( $n=233$ ) were sourced from the population-based Australian Rett Syndrome Database and longitudinal data were used. The Cox proportional hazard model was used to analyse relationships between fracture and prescribed AEDs, mobility, epilepsy diagnosis and genotype.

Results After controlling for mobility, epilepsy diagnosis and genotype, use of valproate increased the risk of fracture threefold after at least 1 year (HR 3.56; $95 \% \mathrm{Cl} 1.85$ to 6.82 ) and after 2 or more years (HR 3.02; $95 \% \mathrm{Cl} 1.90$ to 4.80 ). There was a lesser increased risk (HR 1.99; $95 \% \mathrm{Cl} 0.99$ to 4.02) with lamotrigine in the first year of use but not for subsequent years of use. Carbamazepine slightly decreased the risk (HR 0.60; $95 \% \mathrm{Cl} 0.35$ to 1.02 ) after 2 or more years of use.

Conclusions The effect of valproate on bone health should be considered when managing epilepsy in Rett syndrome. Multiple mechanisms could be contributing to this effect.
\end{abstract}

\section{INTRODUCTION}

Rett syndrome (RTT) is a neurodevelopmental condition associated with physical and intellectual disability. ${ }^{1}$ Reduced bone mineral density (BMD) ${ }^{23}$ and a fracture rate nearly four times that of the general population ${ }^{4}$ have been reported in this condition with the most commonly fractured bone being the femur. The principal genetic cause of RTT is a spectrum of loss-of-function mutations within the $\mathrm{X}$ linked MECP2 gene. ${ }^{5}$ There is evidence that severity of phenotype ${ }^{6}$ and fracture risk ${ }^{4}$ are influenced by the nature of the underlying mutation.

We previously reported that seizures were occurring in approximately $80 \%$ of girls and women with RTT $^{7}$ prompting widespread long-term use of antiepileptic drugs (AEDs) among those affected. ${ }^{8}$ We also found that a diagnosis of epilepsy increases fracture risk, even after adjusting for genotype. ${ }^{4}$ In the present study, we have investigated the association between fracture risk and commonly used AEDs in the same population base, taking into account duration of use, mobility and MECP2 mutation type.

\section{METHODS}

The study was approved by the Princess Margaret Hospital Ethics Committee. Cases were sourced from the population-based Australian Rett Syndrome Database (ARSD), which was

\section{What is already known on this topic}

- Associations between use of antiepileptic drugs (AEDs) and increased risk of fracture have been found in the general population.

- Fracture risk in Rett syndrome is increased and related to genotype and presence of epilepsy.

\section{What this study adds}

- Fracture risk is particularly associated with valproate use compared with other AEDs.

- The impact on bone health should be factored into the decision-making in relation to choice of AED in Rett syndrome.

established in $1993^{9}$ and includes Australian RTT subjects born since 1976. Data were collected from biennial questionnaires completed by the family or care givers between 1996 and 2004 (excluding 1998) and from a year long calendar study carried out in $2000 .{ }^{8}$ Information on fracture history, AEDs, mobility, age at epilepsy diagnosis and genotype was used for this analysis.

\section{Data management}

Details recorded from the questionnaires about fractures included age at occurrence and location of all fractures experienced over the lifespan of the subject with RTT. A single fracture event was a report of an episode when bone fracture occurred, even if the event resulted in two or more fractures. Age at fracture was calculated from age at 31 December for the year of fracture.

Information on AEDs, including generic name of each drug, start date and duration that each AED was prescribed was extrapolated from follow-up questionnaires and the calendar study. Assumptions for any missing data were as follows:

- If no data were recorded in a previous questionnaire, but were present in a later follow-up year (and no start time was indicated), the start time for AED use was assumed to be midway between the two periods.

- If there were missing data for one questionnaire, but the AED regimen remained the 
same in previous and later follow-up questionnaires, we assumed the regimen had continued unchanged over that period.

- If a discrepancy occurred between two sources of information, we used the data closest to the year of the AED use.

It was possible to construct the medication history in all but one case using these assumptions. Only medications taken by 20 or more subjects (during their life time), excluding the short-term 'rescue' medications (diazepam and midazolam), were considered in the analysis.

Current mobility was recorded at the time of each questionnaire on a 9-point $(0-8)$ Likert scale, with 0 representing the wheelchair-bound subject and 8 unaided mobility as previously described. ${ }^{10}$ Scores for years between surveys were linearly interpolated.

Cases were categorised by MECP2 mutation type, including the p.R106W, p.R133C, p.T158M, p.R168X, p.R255X, p.R270X, p.R294X, p.R306C, C-terminal deletions, early truncating and large deletion mutations. A final group included all other pathogenic mutations.

\section{Data analysis}

The effect of AED exposure, mobility and genotype on fracture risk was assessed using the Cox proportional hazard model (after ensuring adequacy of all assumptions), with a counting process style of input and robust standard errors to account for recurrent fractures. The data set was analysed on a year-of-event basis, with one record per person per year of life. Age censoring was age at 31 December for each year of follow-up. In those who had experienced more than one fracture episode in a calendar year, additional records censored at date of fracture were added. Following a preliminary analysis which showed no increase/decrease in fracture risk after 2 years of use and to avoid assumptions of linear increase in fracture risk over time, it was elected to treat AED exposures as time-varying categorical predictors, calculated as either 0,1 or $2+$ full years of continuous use. In each analysis cases were censored after the AED of interest had been stopped. An epilepsy diagnosis variable was created to act as an indicator of possible use of AEDs other than the AED being investigated and was set to 0 in the years before epilepsy diagnosis and 1 thereafter. The relationships between use of commonly prescribed AEDs and genotype were assessed with Pearson's $\chi^{2}$ tests. Statistical analysis was performed with STATA V.9.

\section{RESULTS}

A total of 288 cases were known to the ARSD when the 2004 follow-up questionnaire was administered. The families of 240 cases had provided at least one follow-up questionnaire since 1996, with 233 families providing information relating to the occurrence of fractures. At the time of censoring the median age of all girls/women was 14.7 years (range 2-29 years), 191 (82.0\%) had a diagnosis of epilepsy and $84(36.1 \%)$ had experienced at least one episode of fracture. Fifty-two $(22.3 \%)$ had had one fracture episode, 18 (7.7\%) two fracture episodes, seven $(3.0 \%)$ three and six (2.6\%) four or more. The median level of mobility on the 9-point Likert scale for subjects at 5 years of age was 5 (range $0-8$ ), representing walking with assistance and for subjects at 20 years of age was 3 (range $0-8)$, suggesting increased difficulty in walking with age. Genetic testing had been performed in 215/233 (92.3\%) cases,
Table 1 Frequencies and duration of use for the commonly used antiepileptic drugs

\begin{tabular}{lcll}
\hline Medication & $\begin{array}{l}\text { Number (\%) of cases } \\
\text { ever used }\end{array}$ & $\begin{array}{l}\text { Median } \\
\text { duration of } \\
\text { use (years) }\end{array}$ & $\begin{array}{l}\text { Median age } \\
\text { (years) }\end{array}$ \\
\hline Valproate & $134(57.5)$ & 5.4 & 15.8 \\
Carbamazepine & $114(48.9)$ & 4.0 & 17.0 \\
Lamotrigine & $100(42.9)$ & 3.9 & 15.3 \\
Topirimate & $37(15.9)$ & 3.2 & 16.6 \\
Clonazepam & $27(11.6)$ & 3.4 & 16.3 \\
Clobazam & $26(11.2)$ & 3.0 & 15.4 \\
Vigabatrin & $20(8.6)$ & 3.0 & 18.9 \\
Nitrazepam & $7(3.0)$ & 5.6 & 12.9 \\
Combined & $52(22.3)$ & 4.5 & 15.9 \\
benzodiazepines & & & \\
\hline
\end{tabular}

with a pathogenic mutation identified in 164/215 (76.3\%) of those tested.

Valproate, carbamazepine, lamotrigine and benzodiazepines were the most frequently used AEDs (table 1). The number and proportion of other AEDs used by the cohort, in decreasing order of use, included phenytoin (19, 8.2\%), keppra $(12,5.2 \%)$, phenobarbitone $(9,3.9 \%)$, primidone $(3,1.3 \%)$, acetazolamide $(3,1.3 \%)$, sulthiame $(2,0.7 \%)$ and tigiabine $(1$, $0.4 \%)$. Vigabatrin was used by 20 subjects, but for less than 1 complete year in every case and additional analysis for this AED was not conducted. The common pairs of AEDs used are shown in table 2 . There were no statistically significant relationships between the mutation type and use of valproate $(p=0.53)$, carbamazepine $(p=0.82)$, lamotrigine $(p=0.92)$, benzodiazepine medications $(p=0.22)$ or topiramate $(p=0.56)$.

The fracture risks associated with potential confounders are shown in table 3 . Univariable analyses showed that use of valproate for more than 12 months was associated with a threefold increase in fracture risk (HR 3.22; 95\% CI 1.75 to 5.92, $\mathrm{p}<0.001$, HR 3.44; 95\% CI 1.71 to 6.94, $\mathrm{p}<0.001$ (when restricted to mutation positive cases)) when compared to the risk associated with no or any other prescribed AED and that the elevated risk (HR 2.78; 95\% CI 1.88 to 4.13, p $<0.001$, HR 3.16 ; $95 \%$ CI 1.99 to $5.07, \mathrm{p}<0.001$ (when restricted to mutation positive cases)) persisted in subsequent years. Lamotrigine may also increase the risk of fracture (HR 1.95; 95\% CI 0.98 to $3.87, \mathrm{p}=0.06$, HR $2.21 ; 95 \%$ CI 1.06 to $4.63, \mathrm{p}=0.04$ (when restricted to mutation positive cases)) in the first year of use. The risk of fracture occurrence was not significantly altered by carbamazepine, topiramate or benzodiazepines (clobazam, clonazepam and nitrazepam) (table 4).

Taking genotype, diagnosis of epilepsy (as a proxy for use of AEDs other than valproate in cases not currently using valproate) and level of mobility into account, use of valproate on its own, or in combination with any other AED, remained associated with a threefold increased risk of fracture after 1 year (HR 3.56; 95\% CI 1.85 to 6.82, p<0.001, HR 3.58; 95\% CI 1.71 to $7.49, \mathrm{p}<0.001$ (when restricted to mutation positive cases)) and after 2 or more years (HR 3.02; 95\% CI 1.90 to 4.80, $\mathrm{p}<0.001$, HR 3.43; 95\% CI 2.05 to 5.73, $\mathrm{p}=0.001$ (when restricted to mutation positive cases)). Carbamazepine was associated with a slight decrease in the risk of fracture after 2 or more years (HR $0.60 ; 95 \%$ CI 0.35 to $1.02, p=0.06, \mathrm{HR}$ 0.54 ; $95 \%$ CI 0.29 to $0.99, \mathrm{p}=0.05$ (when restricted to mutation positive cases)). The other commonly used AEDs were not associated with an increased or decreased risk of fracture (table 4). 
Table 2 Most commonly prescribed combinations of antiepileptic drugs $^{*}$

\begin{tabular}{|c|c|c|c|}
\hline & Medication 2 & Frequency & $\begin{array}{l}\text { Taking } \\
\text { this pair } \\
\text { only }\end{array}$ \\
\hline \multirow[t]{7}{*}{ Valproate } & Lamotrigine & 67 & 43 \\
\hline & Vigabatrin & 12 & 5 \\
\hline & Clonazepam & 16 & 6 \\
\hline & Clobazam & 15 & 6 \\
\hline & Topiramate & 24 & 5 \\
\hline & Phenytoin sodium & 13 & 5 \\
\hline & Nitrazepam & 2 & 0 \\
\hline \multirow[t]{8}{*}{ Carbamazepine } & Valproate & 62 & 43 \\
\hline & Lamotrigine & 36 & 15 \\
\hline & Vigabatrin & 9 & 4 \\
\hline & Clonazepam & 10 & 3 \\
\hline & Clobazam & 9 & 1 \\
\hline & Topiramate & 14 & 4 \\
\hline & Phenytoin sodium & 12 & 4 \\
\hline & Nitrazepam & 1 & 0 \\
\hline \multirow[t]{6}{*}{ Lamotrigine } & Vigabatrin & 9 & 3 \\
\hline & Clonazepam & 16 & 1 \\
\hline & Clobazam & 15 & 1 \\
\hline & Topiramate & 26 & 6 \\
\hline & Phenytoin sodium & 5 & 1 \\
\hline & Nitrazepam & 3 & 1 \\
\hline \multirow[t]{2}{*}{ Topiramate } & Phenytoin sodium & 2 & 0 \\
\hline & Nitrazepam & 1 & 0 \\
\hline \multirow[t]{4}{*}{ Clonazepam } & Clobazam & 6 & 1 \\
\hline & Topiramate & 5 & 1 \\
\hline & Phenytoin sodium & 2 & 1 \\
\hline & Nitrazepam & 2 & 0 \\
\hline \multirow[t]{3}{*}{ Clobazam } & Topiramate & 8 & 0 \\
\hline & Phenytoin sodium & 3 & 0 \\
\hline & Nitrazepam & 1 & 0 \\
\hline \multirow[t]{5}{*}{ Vigabatrin } & Clonazepam & 3 & 0 \\
\hline & Clobazam & 1 & 0 \\
\hline & Topiramate & 3 & 0 \\
\hline & Phenytoin sodium & 1 & 0 \\
\hline & Nitrazepam & 0 & 0 \\
\hline
\end{tabular}

${ }^{*}$ Simultaneous use and possibly with additional antiepileptic drugs.

Table 3 Cox regression univariable analysis of fracture risk associated with individual mutations, ${ }^{*}$ diagnosis of epilepsy and mobility level

\begin{tabular}{lcll}
\hline & \multicolumn{2}{c}{ Number (\%) of cases HR (p value) } & CI \\
\hline No mutation & $50(21.4)$ & Baseline & - \\
p.R106W & $5(2.1)$ & $1.16(0.86)$ & $(0.22$ to 6.19$)$ \\
p.R133C & $12(5.2)$ & $0.64(0.42)$ & $(0.22$ to 1.87$)$ \\
p.R168X & $19(8.2)$ & $1.83(0.08)$ & $(0.92$ to 3.63$)$ \\
p.R255X & $10(4.3)$ & $2.66(0.14)$ & $(0.72$ to 9.76$)$ \\
p.R270X & $16(6.9)$ & $2.86(0.03)$ & $(1.11$ to 7.35$)$ \\
p.R294X & $15(6.4)$ & $0.73(0.57)$ & $(0.25$ to 2.12$)$ \\
p.R306C & $11(4.7)$ & $1.17(0.74)$ & $(0.46$ to 2.96$)$ \\
p.T158M & $19(8.2)$ & $1.41(0.46)$ & $(0.57$ to 3.49$)$ \\
C-terminal deletions & $21(9.0)$ & $0.76(0.58)$ & $(0.28$ to 2.01$)$ \\
Early truncations & $11(4.7)$ & $0.96(0.93)$ & $(0.34$ to 2.69$)$ \\
Large deletions & $11(4.7)$ & $1.47(0.33)$ & $(0.67$ to 3.23$)$ \\
Other mutations & $18(7.7)$ & $2.05(0.15)$ & $(0.76$ to 5.51$)$ \\
Epilepsy & - & $1.89(0.01)$ & $(1.17$ to 3.05$)$ \\
Mobility & - & $0.92(0.02)$ & $(0.85$ to 0.99$)$ \\
\hline
\end{tabular}

*15 cases not tested for $M E C P 2$ mutations.
Use of valproate as a monotherapy (compared to cases using no other medication) was associated with more than three times the risk of fracture in both the univariate and multivariable models (table 4). However, use of carbamazepine as a monotherapy (compared to cases using no other medication) showed no significant effect on fracture risk after 1 year, or 2 or more years of use, in the univariate or multivariable model (table 4). All analyses were repeated including only cases with pathogenic MECP2 mutations ( $\mathrm{n}=183$ ) with similar results to the analyses including all clinically diagnosed RTT cases (already shown in table 4).

\section{DISCUSSION}

A high proportion ( $80 \%)$ of RTT subjects in this study had epilepsy. The most frequently prescribed AEDs were valproate, carbamazepine and lamotrigine, with valproate commonly used in combination with carbamazapine or lamotrogine. After controlling for mutation type and mobility, use of valproate for more than 1 year was associated with a threefold increase in risk of fracture.

Fracture is the main clinical end point of interest when considering bone health. To our knowledge, this is the first reported longitudinal study examining the potential relationship between specific AEDs and fracture risk in a chronic neurological condition with the associated co-morbidities of severe intellectual disability and constrained mobility. Data were collected over 8 years from a long-standing RTT populationbased register ${ }^{9}$ and thus the potential for missing information due to recall errors was reduced. Furthermore, mutation data were available on the majority of subjects, making this study the first to include the role of genotype as a moderator variable in the analysis of relationships between fracture and AED use in a specific neurological disorder.

Nevertheless, we did not have access to radiological information to confirm reports of fracture. The mechanism of fracture was not always reported and we were unable to identify the proportion of fractures prompted by the seizures themselves. As information was provided by parents and care givers, changes in care giver could have resulted in difficulties recalling changes in medication regimens. Theoretically, the use of progesterone-only medications or gonadotropin-releasing hormone analogues for menstrual suppression could increase fracture risk in older subjects. However, since in our study population these medications were used by only a few subjects and for a limited time period we were unable to investigate these theoretical risks in this study.

We observed that the risk of fracture was elevated for valproate, prescribed on its own or in combination with other AEDs after 1 or more years. This is practical information of relevance to the management of childhood epilepsy in a complex neurological condition and consistent with two earlier population studies studying mostly adults with idiopathic epilepsy. ${ }^{11}{ }^{12}$ Souverein et a ${ }^{11}$ found a one-and-a-half times risk of fracture in patients taking valproate alone, compared to taking no or any other AED medication. After adjustment for prior fracture, use of corticosteroids, co-morbidity, social variables and a diagnosis of epilepsy Vestergaard et al ${ }^{2}$ found a small increase in the risk of fracture if valproate was ever used. A retrospective study ${ }^{13}$ found a relationship between valproate use and fracture in 50 children and adults with a severe physical and intellectual disability and epilepsy. However, only 14 subjects sustained a fracture, the number prescribed valproate was unspecified and the wide CI limit the usefulness of the findings. In another study of children with cerebral palsy, 
Table 4 Univariable and multivariable* risks of fracture for most frequently used antiepileptic drugs (in combination and as monotherapy alone)

\begin{tabular}{|c|c|c|c|c|c|}
\hline \multirow[b]{2}{*}{ Medication } & \multirow{2}{*}{$\begin{array}{l}\text { Years } \\
\text { of use }\end{array}$} & \multicolumn{2}{|c|}{ Univariable risk } & \multicolumn{2}{|c|}{ Multivariable risk } \\
\hline & & HR (p value) & Cl & HR (p value) & CI \\
\hline \multicolumn{6}{|c|}{ In combination with another AED or as monotherapy } \\
\hline \multirow[t]{3}{*}{ Valproate } & 0 & 1.00 & - & 1.00 & - \\
\hline & 1 & $3.22(<0.001)$ & 1.75 to 5.92 & $3.56(<0.001)$ & 1.85 to 6.82 \\
\hline & 2 or more & $2.78(<0.001)$ & 1.88 to 4.13 & $3.02(<0.001)$ & 1.90 to 4.80 \\
\hline \multirow[t]{3}{*}{ Carbamazepine } & 0 & 1.00 & - & 1.000 & - \\
\hline & 1 & $0.74(0.61)$ & 0.23 to 2.35 & $0.63(0.44)$ & 0.19 to 2.03 \\
\hline & 2 or more & $0.70(0.16)$ & 0.42 to 1.16 & $0.60(0.06)$ & 0.35 to 1.02 \\
\hline \multirow[t]{3}{*}{ Lamotrigine } & 0 & 1.00 & - & 1.00 & - \\
\hline & 1 & $1.95(0.06)$ & 0.98 to 3.87 & $1.99(0.09)$ & 0.99 to 4.02 \\
\hline & 2 or more & $0.94(0.83)$ & 0.56 to 1.60 & $0.94(0.66)$ & 0.53 to 1.66 \\
\hline \multirow[t]{3}{*}{ Topiramate } & 0 & 1.00 & - & 1.00 & - \\
\hline & 1 & $1.89(0.28)$ & 0.60 to 5.99 & $1.98(0.25)$ & 0.62 to 6.35 \\
\hline & 2 or more & $1.07(0.89)$ & 0.43 to 2.64 & $1.24(0.65)$ & 0.49 to 3.14 \\
\hline \multirow[t]{3}{*}{ Benzodiazepines } & 0 & 1.00 & - & 1.00 & - \\
\hline & 1 & $1.05(0.95)$ & 0.26 to 4.26 & $1.13(0.98)$ & 0.27 to 4.64 \\
\hline & 2 or more & $1.24(0.52)$ & 0.64 to 2.38 & $1.15(0.79)$ & 0.54 to 2.46 \\
\hline \multicolumn{6}{|l|}{ As monotherapy only } \\
\hline \multirow[t]{3}{*}{ Valproate } & 0 & 1.00 & - & 1.00 & - \\
\hline & 1 & $3.21(0.005)$ & 1.41 to 7.29 & $3.24(0.01)$ & 1.29 to 8.16 \\
\hline & 2 or more & $3.67(<0.001)$ & 2.16 to 27 & $3.57(0.001)$ & 1.73 to 7.40 \\
\hline \multirow[t]{3}{*}{ Carbamazepine } & 0 & 1.00 & - & 1.000 & - \\
\hline & 1 & $1.46(0.55)$ & 0.44 to 4.83 & $1.10(0.89)$ & 0.31 to 3.93 \\
\hline & 2 or more & $0.83(0.70)$ & 0.33 to 2.07 & $0.64(0.40)$ & 0.24 to 1.77 \\
\hline
\end{tabular}

* Risks of fracture after controlling for mobility, genotype and diagnosis of epilepsy.

AED, antiepileptic drug.

valproate was estimated to contribute $5 \%$ of the variance of fracture. ${ }^{14}$ Although consistent with these earlier findings, the magnitude of the increased fracture risk associated with valproate was greater in our study.

The risk of fracture in our RTT population was not additionally increased for medications such as vigabatrim, topirimate or benzodiazepines, or longer-term use of lamotrigine. Use of carbamazepine may be slightly protective of fracture, when used for longer than 2 years. The limited findings in the literature relating to these other AEDs are mixed, with carbamazepine associated with increased ${ }^{11} 12$ or no increased risk ${ }^{13} 14$ and clonazepam associated with increased ${ }^{12}$ or no increased risk $^{13} 14$ of fracture.

Although not reported consistently, valproate has generally found to be associated with reduced BMD..$^{15}$ Evidence that valproate stimulates osteoclast activity suggests that increased bone resorption may be the mechanism responsible for the valproate-associated reduction of BMD. ${ }^{16}$ Another important question is whether the increased rate of fractures associated with valproate is specifically higher in RTT. Valproate is an inhibitor of class I histone deacetylases (HDACs) (HDACs 1-3) and the class II HDACs 4,5 and $7 .{ }^{17} \mathrm{HDACs}$ play an important role in modulating chromatin structure and gene transcription, with deacetylated chromatin tending to be more compact with an associated reduction in gene expression. The MECP2 gene, which is disrupted by inactivation mutations in RTT cases, offers binding sites for HDACs 1,2 and 8 . The potential functional overlap of consequences of $M E C P 2$ deficiency and valproate activity may aggravate the risk of valproate toxicity in RTT. Support for an inherent effect of MECP2 mutations on bone mineralisation could be speculated in the light of the findings of Haas et al, who showed that females with RTT have lower bone density compared to a similar group with cerebral palsy. ${ }^{3}$ We have previously shown that those with the p.R270X or p.R168X mutations are more likely to fracture. ${ }^{4}$ It would therefore seem that there are complex links between mutation, bone health and AEDs in RTT and additional investigations of these potential interactions are warranted.

Published literature from Sweden, Germany and Australia ${ }^{8}$ 1819 suggests that valproate and carbamazepine are among the three most commonly used first-line AEDs in RTT. There are few clinical trials of epilepsy management in intellectual disability and the relative efficacy of each medication is unclear. ${ }^{20}$ People with RTT are known to have generalised or partial seizures ${ }^{18}$ although information is lacking on the full spectrum of seizure classification. Valproate is considered the preferred drug for the general population of patients with generalised and unclassified epilepsies ${ }^{21}$ and was the most commonly used medication in our RTT population. Carbamazepine is widely accepted as a drug of first choice for partial onset seizures, although lamotrigine has been shown to be equally useful. ${ }^{22}$ We previously reported from data collected on RTT seizure frequency in $2000^{8}$ that those subjects who were on monotherapy with valproate or carbamazepine, or a combination of the two, had reasonably controlled seizures with a median of one or less per month. However, in a series of 110 females with confirmed MECP2 mutations, Huppke et al ${ }^{19}$ found that use of carbamazepine was more likely than valproate to result in a longer seizurefree period. This might suggest that carbamazepine, rather than valproate, should be the first choice of AED in RTT. However, epilepsy prevalence was lower in the German ${ }^{19}$ than in the Australian ${ }^{7}$ and Swedish ${ }^{18}$ studies and their sample was not population-based. Moreover, unlike our research 
that involved the administration of four questionnaires over 8 years, the German study administered only one questionnaire, allowing the possibility of recall bias as the time between initiation of therapy and questionnaire completion increased. No information was provided on response and it is conceivable that there could also have been a bias towards retention of milder cases with a less complicated and easier to recall medication history. However, given carbamazepine's known adverse effects in unclassified and some generalised epilepsies and its possible contributions to seizure exacerbation and cognitive regression, ${ }^{23}$ one needs to be cautious about blanket recommendations regarding its use. Despite its effectiveness, valproate also has potential drawbacks including side effects such as tremor and weight gain; idiosyncratic reactions such as impaired liver function, thrombocytopenia and pancreatitis; and in early pregnancy, an increased risk of congenital abnormalities. ${ }^{24}$ We would recommend that AEDs other than valproate also be considered when planning epilepsy management in RTT, both to avoid current episodes of fracture and as part of a larger plan to optimise bone health for the later years. However, where valproate remains the preferred drug it is particularly important to have other strategies in place to maximise bone health. What we still do not know is whether the effect we have seen with valproate in RTT is of equal magnitude in children with other causes of epilepsy.

Acknowledgements The authors would like to acknowledge the funding of the major aspects of the Australian RTT program by the National Institutes of Health (5R01HD043100-05) and also the National Health and Medical Research Council (NHMRC) under project grant 303189 for the clinical aspects. HL is funded by NHMRC program grant 353514 . We would also like to acknowledge the molecular work carried out under the guidance of Professor John Christodoulou and Dr Bruce Bennetts in Sydney and Dr Mark Davis in Perth. We would especially like to express our sincere gratitude to all the families who have contributed to the study completing questionnaires; the Australian Paediatric Surveillance Unit (APSU) and the RTT Association of Australia who facilitated case ascertainment in Australia. The APSU is a Unit of the Division of Paediatrics, Royal Australasian College of Physicians and is funded by the Department of Health and Ageing and the Faculty of Medicine of the University of Sydney.

Funding National Institutes of Health (US) and National Health and Medical Research Council (Australia).

Competing interests None.

Ethics approval This study was conducted with the approval of the Princess Margaret Hospital for Children, West Perth, Western Australia.

Provenance and peer review Not commissioned; externally peer reviewed.

Contributors Authors have contributed to conception and design $(H L, H W, J D, L J$, $A B, P J)$, or acquisition of data $(H L, A B, L J)$ or analysis $(A B, P J)$ and interpretation of data (all authors); drafting the article (JD, HL, AB, HW, DR, LN) or revising it critically for important intellectual content (all authors); final approval of the version to be published (all authors).

\section{REFERENCES}

1. Hagberg B, Hanefeld F, Percy A, et al. An update on clinically applicable diagnostic criteria in Rett syndrome. Comments to Rett Syndrome Clinical Criteria Consensus Panel Satellite to European Paediatric Neurology Society Meeting, Baden Baden, Germany, 11 September 2001. Eur J Paediatr Neurol 2002;6:293-7.

2. Cepollaro C, Gonnelli S, Bruni D, et al. Dual X-ray absorptiometry and bone ultrasonography in patients with Rett syndrome. Calcif Tissue Int 2001;69:259-62.

3. Haas RH, Dixon SD, Sartoris DJ, et al. Osteopenia in Rett syndrome. J Pediatr 1997; 131:771-4

4. Downs J, Bebbington A, Woodhead $\mathrm{H}$, et al. Early determinants of fractures in Rett syndrome. Pediatrics 2008;121:540-6.

5. Amir RE, Van den Veyver IB, Wan M, et al. Rett syndrome is caused by mutations in X-linked MECP2, encoding methyl-CpG-binding protein 2. Nat Genet 1999;23:185-8.

6. Bebbington A, Anderson A, Ravine D, et al. Investigating genotype-phenotype relationships in Rett syndrome using an international data set. Neurology 2008;70:868-75.

7. Jian L, Nagarajan L, de Klerk N, et al. Predictors of seizure onset in Rett syndrome. J Pediatr 2006;149:542-7.

8. Jian L, Nagarajan L, de Klerk N, et al. Seizures in Rett syndrome: an overview from a one-year calendar study. Eur J Paediatr Neurol 2007;11:310-17.

9. Colvin L, Fyfe S, Leonard S, et al. Describing the phenotype in Rett syndrome using a population database. Arch Dis Child 2003;88:38-43.

10. Ellaway C, Peat J, Leonard H, et al. Sleep dysfunction in Rett syndrome: lack of age related decrease in sleep duration. Brain Dev 2001;23 (Suppl 1):S101-3.

11. Souverein PC, Webb DJ, Weil JG, et al. Use of antiepileptic drugs and risk of fractures: case-control study among patients with epilepsy. Neurology 2006;66:1318-24.

12. Vestergaard $\mathbf{P}$, Rejnmark L, Mosekilde L. Fracture risk associated with use of antiepileptic drugs. Epilepsia 2004;45:1330-7.

13. Kawada T. Factors influencing bone fractures in severely disabled persons. Am J Phys Med Rehabil 2002;81:424-8.

14. Leet AI, Mesfin A, Pichard C, et al. Fractures in children with cerebral palsy. J Pediatr Orthop 2006;26:624-7.

15. Gissel T, Poulsen CS, Vestergaard P. Adverse effects of antiepileptic drugs on bone mineral density in children. Expert Opin Drug Saf 2007;6:267-78.

16. Valsamis HA, Arora SK, Labban B, et al. Antiepileptic drugs and bone metabolism. Nutr Metab (Lond) 2006;3:36.

17. Kostrouchová M, Kostrouch Z, Kostrouchová M. Valproic acid, a molecular lead to multiple regulatory pathways. Folia Biol (Praha) 2007:53:37-49.

18. Steffenburg U, Hagberg G, Hagberg B. Epilepsy in a representative series of Rett syndrome. Acta Paediatr 2001;90:34-9.

19. Huppke P, Köhler K, Brockmann K, et al. Treatment of epilepsy in Rett syndrome. Eur J Paediatr Neurol 2007;11:10-16.

20. Beavis J, Kerr M, Marson AG. Pharmacological interventions for epilepsy in people with intellectual disabilities. Cochrane Database Syst Rev 2007;3:CD005399.

21. Marson AG, Al-Kharusi AM, Alwaidh M, et al. The SANAD study of effectiveness of valproate, lamotrigine, or topiramate for generalised and unclassifiable epilepsy: an unblinded randomised controlled trial. Lancet 2007;369:1016-26.

22. Marson AG, Al-Kharusi AM, Alwaidh M, et al. The SANAD study of effectiveness of carbamazepine, gabapentin, lamotrigine, oxcarbazepine, or topiramate for treatment of partial epilepsy: an unblinded randomised controlled trial. Lancet 2007;369:1000-15.

23. Prasad AN, Stefanelli M, Nagarajan L. Seizure exacerbation and developmental regression with carbamazepine. Can J Neurol Sci 1998;25:287-94.

24. Rowan AJ. Valproate. In: Engel J, Pedley T, eds. Epilepsy: a comprehensive textbook. Vol II. Philadelphia: Lippincott-Raven Publishers, 1998:1599-1607. 